danger." "It may, however, play an important part in aggravating the consequences of a firedamp explosion." I had myself keenly felt how difficult it would be after a verdict of this kind, emanating from such high authorities, to make further progress in the work of convincing practical mining men of the truth of the views I had previously advocated in the pages of the Royal Society's Proceedings. For that reason, and in the absence of some powerful weapon wherewith to meet the French Commissioners with some chance of success, I have hitherto desisted from doing battle with them, although I have been satisfied they were in error from the first. The required weapon has been provided by Herr Hilt, the spokesman of the Prussian Commission, and may now, I think, be made use of without much fear of future contradiction.

Speaking of coal-dust from Pluto Mine, in Westphalia, Herr Hilt says, as the outcome of a long series of practical experiments on the largest scale yet attempted: "Es kann keinem Zweifel unterliegen dass mann mit dieser Staubsorte bei Verlängerung der Strecke und Streuung auch der Flamme eine beliebige Länge würdegebenkönnen. Ganz ähnlich erhält sich der Staub von Neu Iserlohn." Or: "There can be no doubt that with this kind of dust the flame could be lengthened out to any desired extent, provided the gallery and the layer of dust on its floor were made equally long." "The dust of Neu Iserlohn behaves in exactly the same way." 1

After carefully examining the details of this report, I think it not improbable that many, if not most, of the other twenty-four kinds of coal-dust that were subjected to experiment would have given results similar to those which led to the foregoing remarks had they been employed in the same state of minute subdivision. Differences in chemical composition do not appear to have as much effect in controlling the length of flame produced by a given dust under a certain set of conditions as the comparative fineness of the particles of which it is composed. In order to show the effect of fineness Herr Margraf has divided the dusts into five classes, as follows :-

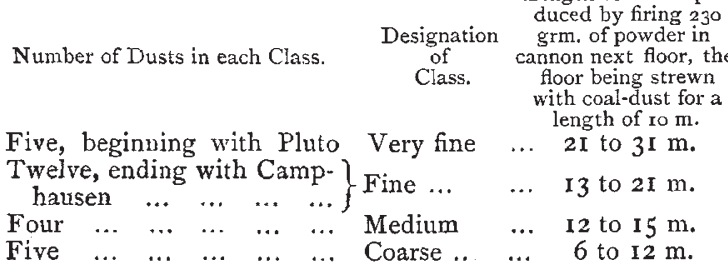

Some experiments were also made with dust passed through sieves having meshes of various widths, which showed that the finer the state of subdivision, the longer was the corresponding flame.

From this it is obvious that before anything definite can be ascertained regarding the infuence of chemical composition, it will be necessary to reduce the dusts to a uniform standard of fineness. Herr Margraf proposes to do this by passing them through a sieve with meshes I $\mathrm{mm}$. wide. I am afraid, however, that some more exact method of effecting a separation of the very fine from the moderately fine particles will have to be resorted to before a satisfactory result can be looked for. A current of air ascending slowly at a uniform rate would be a better means than any conceivable kind of sieve.

I have on several previous occasions pointed out that when a colliery explosion has been begun in a dry mine the coarser particles of coal-dust are winnowed from the finer ones by the blast of air which sweeps through the workings in advance of the flame. It seems to me that

I It may be instructive to compare this conclusion with the second sentence of No. I paper, "On the Influence of Coal-dust in Colliery ExploI879; the conclusion of No. 3 paper, ibid., 188r.-(Abstract). under these circumstances experiments made with any other than the finest particles of each kind of dust can serve no practicable purpose whatever, and that any general conclusions drawn from them must necessarily be misleading. It is further highly probable that this is the rock upon which the French Commission was shipwrecked.

They had ascertained by actual experiment that, as the coarser particles of any given dust were removed by sifting, the flame produced under the same set of conditions became longer and larger in proportion to the fineness of the remaining dust. Yet they failed to carry the argument to its legitimate conclusion. They appear to have been misled either by too much speculation, or by the negative results of their experiments, due, it may be, to the smallness of the scale upon which they were made. They finally pronounced coal-dust to be an element of very secondary importance in colliery explosions, thereby allowing a splendid opportunity to slip from their grasp. The Prussian Commissioners were not slow to take advantage of the opening thus afforded them. Thanks partly to the large scale upon which they have set to work; partly to the natural fineness of Pluto and Neu Iserlohn dust, they have been fortunate in obtaining a series of positive results which amply confirm those previously obtained with the somewhat smaller apparatus belonging to the Lords of Committee of Council on Education set up in this country under the auspices of the Royal Society (No. IV. paper, "On the Influence of Coal-dust in Colliery Explosions," Proc. Roy. Soc., 1881).

The dust brought from Camphausen Colliery does not appear to stand very high on Herr Margraf's list, and yet, since the publication of the memoir, that colliery has been devastated by one of the most violent explosions on record, in which it is admitted, I believe, that coal-dust, and not fire-damp, was the principal agent of destruction. Are we to conclude from this that the nine dusts which lie between Pluto and Camphausen in the order of relative danger are equally liable to produce a flame of indefinite length under like favourable conditions? and, if so, is it not obvious that the experiments are not as reliable as might be wished, since they fail to tell us so?

Before concluding, I might mention that Herr Hilt refers to and agrees with a remark made by MM. Mallard and Le Chatelier to the effect that the method of experiment followed by Sir Frederick Abel and myself when using the apparatus described in my first paper was "too little exact" to determine accurately what percentage of gas is required to render a mixture of coal-dust and air inflammable. My earliest experiments here referred to were made with the view of finding, if possible, some rational explanation of great colliery explosions which up to that time appear to have baffled every attempt to grapple with them, and were not intended to form a kind of counterpart on the large scale of the exact eudiometric processes resorted to in the laboratory. At the same time I may state, however, that, so far as I have been able to ascertain by reading and observation, the methods then employed will compare not unfavourably, as regards exactness, with any that have succeeded them, not excluding those of the Prussian Wetter-Commission.

W. Galloway

\section{THE FAUNA OF RUSSIAN CENTRAL ASIA}

U NTIL within the last thirty years Turkistan has been unknown to science, and what is now ascertained concerning its fauna and flora is for the most part inaccessible to the scientific world because written in Russian. Not that autoptic writers of eminence upon the zoology of the country are numerous. They do not number a dozen, the names most conspicuous being Prjevalsky, Alpheraky, Bogdanoff, Severtsoff, and especially Fedchenko. Prjevalsky's routes do not touch mine, except in the Kuldja 
region, where also Alpheraky travelled, and collected Lepidoptera, with a list of which he has favoured me. To Bogdanoff and Severtsoff I am indebted for information not previously published in English, whilst in connection with the immense work that bears Fedchenko's name I have had the valuable help of Madame Olga Fedchenko, who both accompanied her husband on his scientific journeys and, after his lamented death, edited his works. When I add that I have before me proofs of between three and four thousand species of fauna and flora, in about twenty lists with introductions, the scientific reader will not need to be told that in the compass of a single article I can but touch the fringe of the subject. I have ventured to think, however, the readers of NATURE might be interested in a plain statement that would give some idea of the little-known fauna of Turkistan, as well as indicate what I hope to publish shortly in fuller form.

The part of Russian Central Asia through which I recently travelled, and with which this paper will be mainly concerned, lies between the Oxus and Irtish Rivers, and between the 38 th and 5 oth parallels of north latitude, which region comprises vertically all altitudes from the salt plains, 600 feet above the sea, to the mountain plateaus of the Pamir, i 5,000 feet high.

The species of mammals in Turkistan exceed 80 in number. Among them may be mentioned 7 species of bats, the long-eared hedgehog, and the white-clawed bear. To these must be added the badger, otter, and other Mustelide, including three species of marten. Of the last I was able to secure some skins and skeletons, which are now in the British Museum. The wolf abounds; also a wild dog ; 3 species of fox ; the tiger, snow-leopard, cheetah, and other cats. The salt-plains are frequented by the souslik, and many other rodents, including the hairy-nosed porcupine. To these should be ad led the Persian gazelle, the Saiga antilope, the Siberian ibex, and the Maral stag. I saw at Kuldja and Tashkend specimens of the skull and horns of the Thian Shan sheep, which is bigger than a donkey. The horn is more than four times the length of the skull, and the head complete weighs upwards of 70 lbs. The yak is kept by the KaraKirghese. 'The Russians, too, as an experiment, have introduced some cross-breeds into the plains.

The birds of Turkistan number nearly 400 species, to which may be added 27 frequenting the Pamir. The diurnal birds of prey, such as vultures, eagles, hawks, \&c., number 36 species, some of which the Kirghese train for hunting. Of nocturnal birds of prey there are 9 species of owls. There are thirteen species of crows, and no less than 40 of the finch family, including a new species of sparrow. The thrush family is represented by the blackbird, black-throated, misletoe, and some other thrushes. There are more than 40 of the warbler family, many of them being known in Western Europe, such as the greater nightingale, the bluethroat, redstart, redbreast, and others. Six species of the titmouse family are found in Turkistan, only one of which, however, the well-known oxeye, is common also to England. Two species of dipper are found throughout the country, and other small birds are the Nepalese and European wrens, the Syrian nuthatch, and no less than Io forms of wag-tails. Of pipits there are 7 species, and 14 of larks. The hoopoe I saw when coming south from Sergiopol, and again in the streets of Vierny. Other Turkistan birds are the bee-eaters, the three-toed woodpecker, the ubiquitous cuckoo, and the wonderful Pallas's sand-grouse, which last, some twenty years ago, invaded Europe in such an astonishing way.

Among gallinaceous or game birds are found in Turkistan the black grouse, the capercailie, four species of partridge, the quail, Mongolian pheasant, pea-fowl, and common cock. Of the swan, goose, and duck tribes there are nearly 30 species. Wading-birds, again, are found in great variety, and among them a red-billed curlew, thought at first to be a new species. It has red legs, and a remarkably long red beak, bent at the end, and well adapted for picking up worms from between the pebbles of the beds of the mountain streams is frequents.

Reptiles are represented in Turkistan by 33 species of lizards, vipers, and tortoises. Of the last I tried to bring for the Zoological Gardens a species (Homopus horsfieldi), and it travelled asleep with me some hundreds of miles from Tashkend, but on approaching Odessa it was found to be the sleep of death. Almost all the serpents are non-venomous. Of amphibians there are five species, including the edible frog and green toad.

The fishes of Turkistan are, composed half of European and half of Asiatic forms. The European forms belong principally to the lower course of the Syr-daria, Amudaria, and part of the Zarafshan, whilst certain genera belong exclusively, so far as is known, to the high mountainous countries of Central Asia. The total number of Turkistan species probably exceeds fifty. Of these twentyfive at least belong to the carp family, and there are taken besides sturgeon, trout, pike, barbels, gudgeon, rudd, roach, bleak, bream, loaches, and perch. The fishes of the Zarafshan are particularly noticeable. Of fifteen species found therein not less than five belong to genera met with in numbers in Kabul, Kashmir, Nepal, and the Himalayas. To one of these genera belongs the Marinka, remarkable for its poisonous eggs. The greatest find, however, among the ichthyological fauna of Turkistan has been the Scaphirhynchus, of great importance, not only from a zoological, but also a biological point of view, on account of the extreme smallness of its eyes and the rudimentary condition of its air.bladder. This fish, and certain geological questions connected therewith, was referred to in NATURE in connection with a letter on the Oxus that appeared in the Times on January 7 last.

If for Mollusca we enlarge our area to take in Kashgar and Ladak, then we have in "Central Asia" thus formed 93 species known up to the present time, the land snails being scarce in the desert plains as compared with the larger number and more peculiar forms in the mountain regions. Among the fresh-water Mollusca the predominant feature is the large number of air-breathing species which live in stagnant water, and the almost total absence of the genera living in running water. It has been suggested that this scarcity may be due, as in Switzerland, to the low temperature and stony bed of the rivers.

Among the 50 species of Crustacea known in Turkistan there was not discovered for a long time a crayfish; but Madame Fedchenko informs me that one of a variety new to the species hitherto known in Russia has been recently found. Among the Crustacea inhabiting the fresh waters of Russian Central Asia a very large number of West European species is found, and the new species are, in the majority of instances, very similar to the commonest in Central and Southern Europe.

Of the 16 families to which European spiders are said to belong, all, except two groups very limited in number, have their representatives in Turkistan. The 146 species known there belong to 55 genera, which constitute approximately one-half of the total of European genera. The Tarantula are remarkable in that there are found in the Zarafshan Valley forms which in Europe are met with in countries far apart from each other, and have been reckoned as different species. The most widely distributed form is that with the lower part of the abdomen quite black; next comes the form with coloured edges; and, finally, that with the lower part almost entirely orange. The scorpions of Turkistan are identical with those met with in Trans-Caucasia, and the distribution of one species (Solpuga intrepida) is remarkable. First found in Spain, it was seen later on the Indersk Mountains, then in the Zarafshan Valley, besides which specimens of this harvestman have been found in Viernv. 
The animal is reckoned poisonous, and its bite has in certain cases been followed by death, although nothing is yet known of its poison-apparatus.

The species of Turkistan beetles are estimated at Iooo. I have before me a list of 500 , some of them as yet unpublished. Amongst the most remarkable is the Copris tumulus, the largest specimen measuring one inch and three-quarters long.

The hymenopterous fauna of Turkistan is not yet fully worked out, but I may observe that of Mellifera there are known 438 species, and of Sphegidle upwards of I 50. As regards the latter, the valleys of Ferghana and the Zarafshan do not present many specialities. On the other hand, the Kizil Kum desert abounds in new species and even genera, sharply distinguished from known species both in the form of the body and in the beauty and size of the individuals. There is, moreover, a remarkable similarity between the species belonging to the Kizil Kum and the Egyptian sands. Of Scolizde 30 species are known, whilst of Mutillide I 8 species have been treated by Gen. Radoszkovsky, who informs me that Gen. Komaroff, now military governor of the Trans-Caspian district, has quite recently made scientific explorations between As khabad and Merv, and that among the insects collected by him about Askhabad are six speces of Mutillidce, four of which are marked as new, and one as a new genus. Of 36 species of ants collected in Turkistan, 7 only were new. The Formicidre of the region seem to be very similar to those of South Europe. This is not astonishing, since the mean temperature of a Turkistan summer differs little from the mean summer heat in Southern Europe, and this case only proves once more that, in general, countries with summers alike have greater similarity with regard to fauna and flora than countries lying under identical isotherms with different summers. This peculiarity is evident with regard to Formicidæ, because, for example, in Italy and Turkistan they have an identical summer; and though the winter in Turkistan is long and cold, it does not appear to have much influence over the ants, which are protected therefrom. European species which live in trees and woods appear to be in most cáses absent from Turkistan. Of the new Turkistan species one Ischnomyrmex rhaphidizceps) is specially interesting, as closely allied to two species inhabiting countries between the tropical and subtropical zones of the southern hemisphere. It is remarkable, therefore, to meet with a species of the same genus in the temperate zone of the northern hemisphere, and it may be presumed that these last have existed in Turkistan since the Tertiary period. I have yet to mention Chrysidiformes, of which 53 species have been found in Turkistan, and among them 2 new genera and I5 new species.

Before passing from hymenopterous insects I may mention that, though saw-flies are not numerous in the Zarafshan Valley, yet there is one form particularly remarkable, for, with a normal male, related to the group Selandride is a female without traces of wings. Affected by this absence of wings, the thorax undergoes important changes, and appears greatly swollen, and all the females generally have the appearance of little bags. Its relation to this family is said to be astounding, since it is the only example of the wingless form in the whole family of sawflies. All the other specialities of structure, however, as well as the wings of the male, confirm it.

One of the first lists made of the butterflies and moths of Turkistan enumerated 367 species, of which 122 species were of Microlepidoptera. The great majority (284) were caught in the oases and hilly districts between 750 and 4500 feet above the sea; 4I species also were taken on mountains up to 8000 feet high, and 28 species from 8000 to I3,000 feet. Mr. Alpheraky, of Taganrog, has furnished me with a list in manuscript of 377 species of Lepidoptera collected by him in I879 in the district of Kuldja and the surrounding mountains; but even these two lists together, I am told, give only an incomplcte enumeration of the Lepidoptera of 'Turkistan, which contains a large number of new forms.

As we travelled from Tashkend to Khojend dragon-flies were so numerous that we caught several specimens by extending a butterfly-net from our carriage. The neuropterological fauna, however, of Turkistan is only partially known. Mr. MacLachlan has treated upwards of 60 species, most of them European in character, and many of them belonging even to Western Europe, whilst there is also an unimportant mixture of the Indian element.

There is a mingling again of the Indian element in the orthopterous fauna of Turkistan, but the Indian species are much fewer than the European. This fauna is particularly like that of South Russia, and it contains a large number of West European species. The non-European species are from South Asia, among which are a few from more distant countries, particularly from Africa. The total number of species known in Turkistan exceeds 70. Among them should be mentioned two locusts, and a third called locally Prus. Ravages of the former have been complained of in the neighbourhood of Perovsk and of the "Prus" in the Zarafshan Valley.

Of Hemiptera I have no list of species, but I saw a fine collection at Tashkend, made by Mr. Oshanin.

I come, lastly, to Cestodes, or intestinal worms. Of 47 species known in Turkistan, 2 are found in man, 3 each in the dog and sheep, 2 each in the cat and goat, and 1 each in the horse, ox, and marmot ; 30 are found in birds, 2 in reptiles, and $I$ in fishes. Of all the Vermes the most interesting is what the Bokhariots call the Rishta (Filaria medinensis). The parasite is found at Bokhara and certain adjacent towns in the water of stagnant pools, which the natives drink, and suffer in consequence from the rishta disease. The worm develops under the skin, lengthening at the rate of about an inch in a week, until an abscess is formed, through which the head (as is said) of the parasite appears. The problem, then, is to extract the animal entire. Native specialists insert a needle, and one end is drawn out by the fingers of the right hand, whilst those of the left press the adjacent part. Russian medical men wind off the animal on a reel, so much as comes out daily without force, till the whole, commonly three feet in length, is extracted. If, however, the worm should break, thousands of fresh germs are liberated from the broken part, and the illness continues for several months. I met with an unsuccessful case at Samarkand, and was given by the doctor some picces of the rishta, which I brought in spirits to London.

The appearance of the worm is of a milk-white colour, resembling cooked vermicelli, and it can be stretched like a piece of elastic. The investigations of Prof. Fedcheriko brought to light some very interesting facts concerning the rishla, the first of which was that the germs of the parasite cannot live in very fresh water, which is in keeping with the fact that the parasite appears only in those places where the people are forced to use standing water. The rishtc is the last of the Turkistan fauna that I can mention here, but I hope within a few weeks to publish fuller particulars, through Messrs. Sampson Low and Co., in a new work entitled "Russian Central Asia, including Kuldja, Bokhara, Khiva, and Merv, with Appendices on the Fauna, Flora, and Bibliography of Russian Turkistan." HENRY LANSDELL

\section{FIELD EXPERIMENTS AT ROTHAMSTED ${ }^{1}$}

$\Upsilon \mathrm{HE}$ above Report, forwarded to us, bears the name of no publisher, and is not priced. It therefore may be taken as a private issue, copies of which can only be

1 "Memoranda of the Field Experiments conducted on the Farm and in the Laboratory of Sir John Bennett Lawes, Bart., at Rothamsted, Herts., June, r884." 